\title{
Traffic-related air pollution near roadways: discerning local impacts from background
}

\author{
Nathan Hilker ${ }^{1}$, Jonathan M. Wang ${ }^{1}$, Cheol-Heon Jeong ${ }^{1}$, Robert M. Healy ${ }^{2}$, Uwayemi Sofowote ${ }^{2}$ Jerzy Debosz $^{2}$, \\ Yushan Su², Michael Noble ${ }^{2}$, Anthony Munoz ${ }^{2}$, Geoff Doerksen ${ }^{3}$, Luc White $^{4}$, Céline Audette ${ }^{4}$, Dennis Herod ${ }^{4}$, \\ Jeffrey R. Brook ${ }^{1,5}$, and Greg J. Evans ${ }^{1}$ \\ ${ }^{1}$ Southern Ontario Centre for Atmospheric Aerosol Research, Department of Chemical Engineering and Applied Chemistry, \\ University of Toronto, Toronto, ON, M5S 3E5, Canada \\ ${ }^{2}$ Environmental Monitoring and Reporting Branch, Ontario Ministry of the Environment Conservation and Parks, Etobicoke, \\ ON, M3P 3V6, Canada \\ ${ }^{3}$ Air Quality Policy and Management Division, Metro Vancouver, Burnaby, BC, V5H 0C6, Canada \\ ${ }^{4}$ Air Quality Research Division, Environment and Climate Change Canada, Ottawa, ON, K1A 0H3, Canada \\ ${ }^{5}$ Air Quality Research Division, Environment and Climate Change Canada, Toronto, ON, M3H 5T4, Canada
}

Correspondence: Greg J. Evans (greg.evans@utoronto.ca)

Received: 21 March 2019 - Discussion started: 8 April 2019

Revised: 29 July 2019 - Accepted: 5 August 2019 - Published: 2 October 2019

\begin{abstract}
Adverse health outcomes related to exposure to air pollution have gained much attention in recent years, with a particular emphasis on traffic-related pollutants near roadways, where concentrations tend to be most severe. As such, many projects around the world are being initiated to routinely monitor pollution near major roads. Understanding the extent to which local on-road traffic directly affects these measurements, however, is a challenging problem, and a more thorough comprehension of it is necessary to properly assess its impact on near-road air quality. In this study, a set of commonly measured air pollutants (black carbon; carbon dioxide; carbon monoxide; fine particulate matter, $\mathrm{PM}_{2.5}$; nitrogen oxides; ozone; and ultrafine particle concentrations) were monitored continuously between 1 June 2015 and 31 March 2017 at six stations in Canada: two near-road and two urban background stations in Toronto, Ontario, and one near-road and one urban background station in Vancouver, British Columbia. Three methods of differentiating between local and background concentrations at near-road locations were tested: (1) differences in average pollutant concentrations between near-road and urban background station pairs, (2) differences in downwind and upwind pollutant averages, and (3) interpolation of rolling minima to infer background concentrations. The last two methods use near-road data only, and were compared with method 1 , where an ex-
\end{abstract}

plicit difference was measured, to assess accuracy and robustness. It was found that method 2 produced average local concentrations that were biased high by a factor of between 1.4 and 1.7 when compared with method 1 and was not universally feasible, whereas method 3 produced concentrations that were in good agreement with method 1 for all pollutants except ozone and $\mathrm{PM}_{2.5}$, which are generally secondary and regional in nature. The results of this comparison are intended to aid researchers in the analysis of data procured in future near-road monitoring studies. Lastly, upon determining these local pollutant concentrations as a function of time, their variability with respect to wind speed (WS) and wind direction (WD) was assessed relative to the mean values measured at the specific sites. This normalization allowed generalization across the pollutants and made the values from different sites more comparable. With the exception of ozone and $\mathrm{PM}_{2.5}$, local pollutant concentrations at these near-road locations were enhanced by a factor of 2 relative to their mean in the case of stagnant winds and were shown to be proportional to $\mathrm{WS}^{-0.6}$. Downwind conditions enhanced local concentrations by a factor of $\sim 2$ relative to their mean, while upwind conditions suppressed them by a factor of $\sim 4$. Site-specific factors such as distance from roadway and local meteorology should be taken into consideration when generalizing these factors. The methods used to determine these 
local concentrations, however, have been shown to be applicable across pollutants and different near-road monitoring environments.

\section{Introduction}

Traffic-related air pollutants (TRAPs) are of concern because on-road traffic is often a major source of air pollution in urban environments (Belis et al., 2013; Molina and Molina, 2004; Pant and Harrison, 2013) where population densities are greatest - in Canada, it is estimated that one-third of the population lives within $250 \mathrm{~m}$ of a major roadway (Evans et al., 2011) - and it is within these near-road regions that TRAP concentrations are generally highest (Baldwin et al., 2015; Jeong et al., 2015; Kimbrough et al., 2018; Saha et al., 2018).

As such, there is a growing interest in measuring air pollutant concentrations near roadways in order to better understand TRAP exposure levels in these environments. However, in order to isolate the underlying sources and reasons for elevated concentrations, further processing of raw measurement data is necessary. In general, near-road TRAP concentrations are influenced by both regional and local emissions, and being able to distinguish the contributions of these sources allows their relative impacts to be more properly assessed. Of particular importance to near-road measurements is understanding the role of on-road traffic. For TRAPs whose source(s) cannot be readily identified from their measurement at a singular location, concurrent samples at various locations and/or algorithmic methods can be used to enable apportionment.

Often, determining TRAP background concentrations is accomplished through monitoring at remote, representative locations that are minimally impacted by nearby sources; properly siting background stations in urban environments is in itself a challenge, and not always feasible. This practice, while useful in providing confidence in information regarding background air quality, is expensive because it requires additional monitoring stations and personnel to maintain them. The value of these background stations is lessened if similar knowledge is extractable from near-road locations alone. Various time-series analysis algorithms have been proposed for this purpose, many of which make use of the inverse relation between source proximity and signal frequency. For example, the technique of interpolating minima across time windows of varying length has been applied successfully to data from both mobile laboratories (Brantley et al., 2014; Shairsingh et al., 2018) and stationary measurements (Wang et al., 2018) for the purposes of estimating urban background pollutant concentrations. Additionally, work by Klems et al. (2010) and Sabaliauskas et al. (2014) made use of the discrete wavelet transform, an algorithm used widely in signal compression and de-noising, to ultrafine par- ticle time-series data to determine the time-dependent contribution of local sources to roadside concentrations. Another technique, statistical clustering of air quality data in urban environments, was utilized by Gomez-Losada et al. (2018) to characterize background air quality. Indeed, there are many promising avenues of background-subtracting near-road air quality data.

Given the diversity of techniques available for differentiating local and background pollutant concentrations, as well as the large variety of instrumentation available, it is not clear which approaches are most generalizable or applicable, or whether it is necessary to invest in concurrent measurements at many versus few locations. In addition, the exact definition of what is background air quality is somewhat unclear, and in the context of this study, given the spatial separation between sites (on the order of $10 \mathrm{~km}$ or less), it is assumed to be a measure of background air quality in the urban airshed. Ma and Birmili (2015), in a study of ultrafine particle nucleation, defined measurement locations in their study which were 4.5 and $40 \mathrm{~km}$ from an urban roadside station as urban background and regional background, respectively. The former was presumed to be a measure of regional air quality superimposed with diffuse urban emissions, and it is this definition that best characterizes the background air quality measured in this study. To evaluate whether information regarding this urban background was attainable from near-road measurements alone, two strategies for quantifying the contribution of local on-road traffic to near-road air quality were compared, and their reliability and accuracy were assessed through comparison with tandem measurements in both environments.

In this study, data were collected continuously at three near-road and three urban background monitoring locations for close to 2 years (namely between 1 June 2015 and 31 March 2017). Various gas- and particle-phase pollutants along with meteorological parameters were measured using an array of instrumentation. Concentrations in excess of the urban background were calculated from the near-road data using three techniques, one of which calculated an explicit difference between sites, whereas the other two made use of only near-road data. Comparison of these methodologies addresses whether information regarding background air quality is readily inferable from measurements made in the nearroad environment.

\section{Methods}

\subsection{Measurement locations}

Data were collected from six separate monitoring locations: four of which were in Toronto, Ontario (two situated near roadways and two in urban background environments), with the remaining two located in Vancouver, British Columbia (one situated near a roadway and another in the urban back- 
ground). The location of each station, along with information regarding the major roadway next to which they were located (for the near-road sites), is summarized in Table 1. The two near-road stations in Toronto, NR-TOR-1 (43.7111, $-79.5433)$ and NR-TOR-2 $(43.6590,-79.3954)$, and their respective instrumentation setups have been utilized and reported by others and are described therein (Sabaliauskas et al., 2012; Sofowote et al., 2018; Wang et al., 2015). The NR-TOR-1 site was positioned $10 \mathrm{~m}$ from Highway 401, the busiest highway in North America in terms of annual average daily traffic (AADT) with over 400000 vehicles per day distributed across eight eastbound and eight westbound lanes. The Southern Ontario Centre for Atmospheric Aerosol Research (SOCAAR) served as the second near-road site (NR-TOR-2), and was located $15 \mathrm{~m}$ from College Street in downtown Toronto, which experienced traffic volumes of 17200 vehicles per day on average. The northernmost station in Toronto, BG-TOR-1, was located at Environment and Climate Change Canada (43.7806, -79.4675), $180 \mathrm{~m}$ from the nearest roadway, and the measurements from this station served as an urban background/baseline for NR-TOR-1, which was located $9.8 \mathrm{~km}$ to the southwest of it. The second background station, BG-TOR-2, was positioned on the southernmost point of the Toronto Islands on Lake Ontario (43.6122, -79.3887), and was $5.2 \mathrm{~km}$ south of NR-TOR-2. Since vehicular traffic on the Toronto Islands was limited to a small number of service vehicles, the BG-TOR-2 station was well removed from tailpipe emissions.

The near-road station in Vancouver, NR-VAN, was situated $6 \mathrm{~m}$ from Clark Drive (49.2603, -123.0778), a major roadway that experienced on average 33100 vehicles per day across four southbound and three northbound lanes. Additionally, located $65 \mathrm{~m}$ south of the station was a major intersection, Clark Drive and 12th Avenue, at which there were two gas stations located on the northwest and northeast sides. The effect this intersection had on traffic patterns (stop-andgo especially) directly next to the station and its effect on measured TRAP concentrations are explored in this study. Lastly, the urban background station in Vancouver, BG-VAN, was located $2.2 \mathrm{~km}$ east of NR-VAN at Sunny Hill Children's Hospital (49.2529, -123.0492). This area was relatively removed from traffic emissions because it was located within a neighbourhood zoned predominately for single unit family dwellings.

\subsection{Instrumentation}

A common suite of instrumentation was employed at all stations. Gas-phase pollutants measured include carbon dioxide $\left(\mathrm{CO}_{2} ; 840 \mathrm{~A}\right.$, LI-COR Biosciences; attenuation of infrared radiation at wavelengths of 4.26 and $2.95 \mu \mathrm{m}$ for $\mathrm{H}_{2} \mathrm{O}$ differentiation), carbon monoxide (CO; 48i, Thermo Scientific; attenuation of infrared radiation at a wavelength of $4.6 \mu \mathrm{m}$ ), ozone $\left(\mathrm{O}_{3} ; 49 \mathrm{i}\right.$, Thermo Scientific; attenuation of ultraviolet radiation at a wavelength of $254 \mathrm{~nm}$ ), and nitrogen ox- ides $\left(\mathrm{NO}_{x} ; 42 \mathrm{i}\right.$, Thermo Scientific; infrared chemiluminescence). Particle-phase pollutant properties measured include mass concentration of particles less than $2.5 \mu \mathrm{m}$ in diameter $\left(\mathrm{PM}_{2.5}\right.$; SHARP 5030, Thermo Scientific; beta attenuation and light scattering); particle number concentration (UFP; 651, Teledyne API; water-based condensation particle counting); and black carbon (BC; AE33, Magee Scientific; filter-based attenuation of $880 \mathrm{~nm}$ wavelength light) mass concentration. Additionally, a meteorological sensor (WXT520, Vaisala; ultrasonic anemometer) recorded wind direction, wind speed, ambient temperature, pressure, and relative humidity at each station. Traffic intensities, velocities, and approximate vehicle lengths were measured continuously (SmartSensor HD, Wavetronix; dual beam radar) at the three near-road stations.

Gas-phase instruments were calibrated on-site every 3 months using cylinders of compressed gases at certified concentrations (Linde). One cylinder contained $\mathrm{SO}_{2}, \mathrm{CO}$, and $\mathrm{CO}_{2}$, while the other contained $\mathrm{NO}$; both contained $\mathrm{N}_{2}$ as an inert makeup gas. Dilution and mixing of the gases was accomplished using a dynamic gas calibrator (146i, Thermo Scientific; 6100, Environics) to produce zero checks and span concentrations that were similar to ambient ranges. Additionally, these dynamic gas-phase calibrators contained $\mathrm{O}_{3}$ generators based on ultraviolet (UV) radiation which were used to calibrate the $49 \mathrm{i}$ monitors as well as test the efficiencies of the molybdenum $\mathrm{NO}_{2}$ converters in the $42 \mathrm{i}$ monitors. SHARP 5030 instruments were zero checked using a HEPA filter, had their temperature and relative humidity sensors calibrated, and were span checked using mass standards supplied by Thermo Fisher Scientific twice annually. In addition to recommended monthly maintenance procedures for the API 651, each instrument underwent routine annual calibration by the manufacturer. Flow rates at each station were verified on a monthly basis, and a variable flow rate pump was attached to a stainless steel particle manifold, from which all particle-phase instruments were sampled, to ensure a constant flow rate of $16.7 \mathrm{~L} \mathrm{~min}^{-1}$ to satisfy the $2.5 \mu \mathrm{m}$ cut-off conditions of the inlet cyclone.

\section{Data analysis}

Data acquisition was accomplished using Envidas Ultimate software (DR DAS Ltd.). Quality assurance of the data was performed by the primary operators of each station. This included, among other things: discounting data in which instrument diagnostic parameters were outside of acceptable ranges, omitting calibration times, and flagging suspect periods. Data from this study were acquired at a $1 \mathrm{~min}$ resolution and further averaged to hourly resolution. Only hours containing at least $45 \mathrm{~min}(\geq 75 \%)$ of valid data are reported. Data processing and analysis was done through a combination of SQL (Microsoft), SAS 9.4 (SAS Institute Inc.), and IGOR Pro 6.37 (Wavemetrics Inc.) software. Using the 
Table 1. IDs, locations, name of major roadway, and average daily traffic intensity for each monitoring location.

\begin{tabular}{lrrlrr}
\hline Station ID & Latitude & Longitude & $\begin{array}{l}\text { Major } \\
\text { roadway }\end{array}$ & $\begin{array}{r}\text { Annual average } \\
\text { daily traffic (AADT) }\end{array}$ & $\begin{array}{r}\text { Distance from } \\
\text { roadway (m) }\end{array}$ \\
\hline NR-TOR-1 & 43.7111 & -79.5433 & Highway 401 & 411600 & 10 \\
BG-TOR-1 & 43.7806 & -79.4675 & - & - & - \\
NR-TOR-2 & 43.6590 & -79.3954 & College Street & 17200 & 15 \\
BG-TOR-2 & 43.6122 & -79.3887 & - & - & - \\
NR-VAN & 49.2603 & -123.0778 & Clark Drive & 33100 & 6 \\
BG-VAN & 49.2529 & -123.0492 & - & - & - \\
\hline
\end{tabular}

hourly concentrations in the finalized dataset, three methods of separating local and background concentrations from the near-road measurements were tested. One of these methods made use of the urban background measurements to explicitly infer background concentrations, whereas the other two, downwind-upwind comparison and interpolation of minimum concentrations, estimated background concentrations from the near-road measurements alone.

\subsection{Average site differences}

The first method for determining local pollutant concentrations explored in this paper, henceforth referred to as method 1 , is through the difference between concentrations measured at a near-road location, $C_{\mathrm{NR}}$, and at the nearest urban background location, $C_{\mathrm{BG}}$, for some concurrent observation, $i$. Concentrations associated with local influences determined using method $1, C_{\mathrm{L}, 1}$, rely on the assumption

$C_{\mathrm{NR}}[i]=C_{\mathrm{L}, 1}[i]+C_{\mathrm{BG}}[i]$.

Average $C_{\mathrm{L}, 1}$ values for each near-road location were then determined using Eq. (2):

$\bar{C}_{\mathrm{L}, 1}=\frac{1}{N} \sum_{i=1}^{N}\left(C_{\mathrm{NR}}[i]-C_{\mathrm{BG}}[i]\right)$,

again, $C_{\mathrm{NR}}[i]$ and $C_{\mathrm{BG}}[i]$ are near-road and urban background measurements, respectively, made over a concurrent time interval, $i$. As $N$, the number of observations used in calculating the temporal average, increases, the calculated average difference will encompass more of the variability from meteorological and traffic conditions, and therefore be more representative of an average site difference.

\subsection{Downwind-upwind analysis}

Through association with meteorology at a near-road measurement location, it is possible to assess traffic's influence on TRAP concentrations from the differences between downwind and upwind conditions. For example, Galvis et al. (2013) utilized average downwind and upwind concentrations of $\mathrm{CO}_{2}, \mathrm{BC}$, and $\mathrm{PM}_{2.5}$ from a rail yard to calculate local pollutant concentrations for use in fuel-based emission factor calculations. A similar approach is used here to isolate concentrations emitted from a roadway, henceforth referred to as method 2. Defining ranges of wind directions as corresponding to downwind and upwind of the major street next to which a station is located, average local concentrations from method 2, $C_{\mathrm{L}, 2}$, can be estimated using Eq. (3):

$\bar{C}_{\mathrm{L}, 2}=\frac{1}{N} \sum_{i=1}^{N} C_{\mathrm{DW}}[i]-\frac{1}{M} \sum_{i=1}^{M} C_{\mathrm{UW}}[i]$

where $C_{\mathrm{DW}}$ and $C_{\mathrm{UW}}$ are near-road TRAP concentrations measured when winds originate from downwind and upwind of the major roadway, respectively. Note that the number of points used to compute the averages of these conditions, $N$ and $M$, are not necessarily equivalent, and the times that comprise these two averages are mutually exclusive by definition. For example, if the prevailing wind at a site is downwind of the roadway, then downwind data will naturally occur more frequently than upwind. Figure S1 in the Supplement shows wind frequency data as measured at each nearroad site throughout the monitoring campaign. Similar to method 1 , as the averaging time for both conditions is increased, confidence in $C_{\mathrm{L}, 2}$ will improve. It is also important to note that because these two meteorological scenarios encompass different time frames, it is possible for certain times of day, and other factors to be overrepresented in either average.

In all analyses in which meteorological data are utilized, stagnant periods (wind speed (WS) $<1.0 \mathrm{~m} \mathrm{~s}^{-1}$ ) were omitted. Local concentrations cannot be estimated as a function of time using this method, as downwind and upwind concentrations cannot be measured simultaneously with a single near-road station. Also, stagnant time periods, as well as time periods that are not within the downwind-upwind ranges, are omitted, thereby increasing the amount of time needed to attain a representative average. Lastly, an inherent assumption to this method is that upwind concentrations on either side of the roadway are similar. Depending on the site, however, this assumption may not be accurate. 


\subsubsection{Wind sector definitions at NR-TOR-1}

Defining downwind and upwind sectors at NR-TOR-1 was straightforward, owing to the flat terrain of the area and the lack of nearby TRAP sources excluding those from Highway 401 . Hence, $90^{\circ}$ quadrants perpendicular to the highway axis were chosen. These definitions were further supported by average ambient $\mathrm{CO}_{2}$ concentrations - an indicator of combustion associated with traffic emissions - measured as a function of wind direction, shown in Fig. 1. Thus, downwind conditions at NR-TOR-1 were defined as WD $\geq 295^{\circ}$ or $\mathrm{WD} \leq 25^{\circ}$ and upwind as $115^{\circ} \leq \mathrm{WD} \leq 205^{\circ}$, where WD denotes wind direction as measured locally at the station atop a $10 \mathrm{~m}$ mast.

\subsubsection{Wind sector definitions at NR-TOR-2}

Unlike the NR-TOR-1 site, wind dynamics at NR-TOR-2 were complicated by urban topography; namely, the roadside inlet was within an urban canyon (aspect ratio of $\sim 0.5$ : building heights of $\sim 20 \mathrm{~m}$ on either side and a street width of $\sim 40 \mathrm{~m}$ ) resulting in more stagnant conditions roadside and introducing micrometeorological effects such as in-canyon vortices (Oke, 1988). The effect of urban canyon geometry on micrometeorology is an effect that has been known for some time, and in general, for city-scale wind patterns perpendicular to the street axis, ground-level winds tend to be opposite to those above the urban canopy (Vardoulakis et al., 2003).

Given the urban canyon's effect on ground-level wind direction, downwind-upwind quadrants at NR-TOR-2 were determined based on wind direction measurements made above the urban canopy, and are defined as $\mathrm{WD} \geq 300^{\circ}$ or $\mathrm{WD} \leq 30^{\circ}$ and $120^{\circ} \leq \mathrm{WD} \leq 210^{\circ}$ for downwind and upwind conditions, respectively. Figure 2 shows a satellite image of the site with these respective quadrant definitions, along with average $\mathrm{CO}_{2}$ concentrations as a function of wind direction, similar to Fig. 1. From the range of $\mathrm{CO}_{2}$ concentrations seen here, it is clear that obtaining a precise definition of what exactly is downwind or upwind of College Street is non-trivial. Impact from the intersection southwest (winds from $\sim 230^{\circ}$ ) of the receptor is also somewhat apparent in Fig. 2.

\subsubsection{Wind sector definitions at NR-VAN}

While the presence of two- to three-story buildings within the immediate vicinity of the NR-VAN station may have complicated meteorological measurements to some extent, the role of wind direction in the impact of local traffic emissions was much more evident at this site than it was at NR-TOR2. Other streets in the vicinity of Clark Drive affected the driving patterns near the station - a major intersection (Clark Drive and 12th Avenue) approximately $65 \mathrm{~m}$ south of the station had an impact on average measured $\mathrm{CO}_{2}$ concentrations
(Fig. 3) originating from the SSE direction. Because of this, the downwind and upwind sector definitions for this site were not taken to be orthogonal: instead, downwind was defined as $135^{\circ} \leq \mathrm{WD} \leq 195^{\circ}$ and upwind as $235^{\circ} \leq \mathrm{WD} \leq 315^{\circ}$; these definitions were chosen in accordance with surrounding land usage. While the upwind definition does include 12th Avenue, a major roadway within $120 \mathrm{~m}$ of the station, it is suspected that lower TRAP concentrations from this sector are due to lower traffic volumes on 12th Avenue compared with Clark Drive, truck restrictions on 12th Avenue, and mechanical mixing from surface roughness (i.e. winds carrying TRAPs emitted on 12th being pushed up over the densely spaced buildings between the roadway and monitor, resulting in diluted or no TRAPs measured at ground level). Contrasting this upwind definition with measurements from the sector $315-345^{\circ}$ in Fig. 3, which includes the major roadway Broadway $250 \mathrm{~m}$ from the receptor (farther than 12th), there is a difference in average $\mathrm{CO}_{2}$ concentrations of about $15 \mathrm{ppm}$, and this difference is likely due to reduced surface roughness NNW of the receptor. Both NR-TOR-2 and NRVAN provide examples of the complexity of siting near-road stations and how site-specific considerations must be made when associating data with meteorology.

\subsection{Background subtraction using time series data}

Extracting information from one-dimensional ambient pollution time-series data (i.e. concentration as a function of time) for the purpose of source apportionment is appealing as it allows the possibility of obtaining local and background estimates without the need for more rigorous chemical analysis, computationally expensive multivariate analyses, or measurements made at multiple locations. Such algorithms make use of the underlying principle that signal frequency is inversely related to source distance. Regional or background sources (farther away from a receptor) produce slower-varying, lower-frequency signals, whereas local (nearby) sources, such as traffic, produce faster-varying, higher-frequency signals (Tchepel and Borrego, 2010).

The frequency at which data are acquired limits the highest frequencies separable by such a method. Daily averages, for example, are too lengthy to capture processes whose timescales are much shorter - a plume from a nearby onroad vehicle, for example, would have a characteristic time on the order of seconds to minutes. Therefore, in order to isolate these local temporal fluctuations, relatively high-timeresolution data are necessary. A technique recently developed by Wang et al. (2018) applied to hourly near-road measurements in order to determine above-background pollutant concentrations for use in calculating fleet-averaged emission factors is explored further in this paper. 

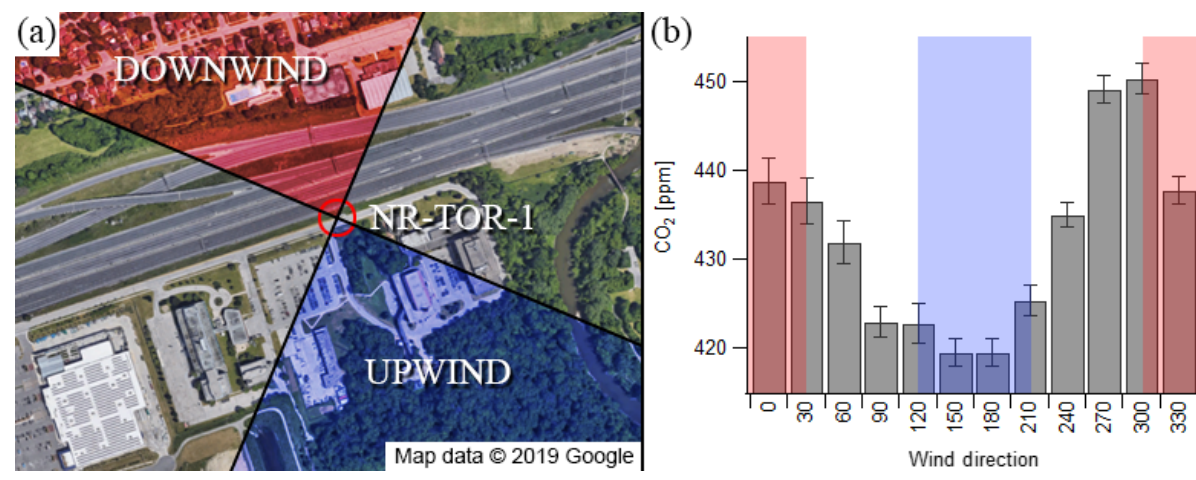

Figure 1. Satellite image of the NR-TOR-1 site, along with upwind (blue) and downwind (red) quadrant definitions. Meteorological measurements were taken on top of a $10 \mathrm{~m}$ mast at the location of the station (labelled: NR-TOR-1) (a). Average ambient $\mathrm{CO}_{2}$ concentrations by wind direction, with upwind and downwind definitions again highlighted in blue and red, respectively. Error bars are $95 \%$ confidence intervals on the mean (b).
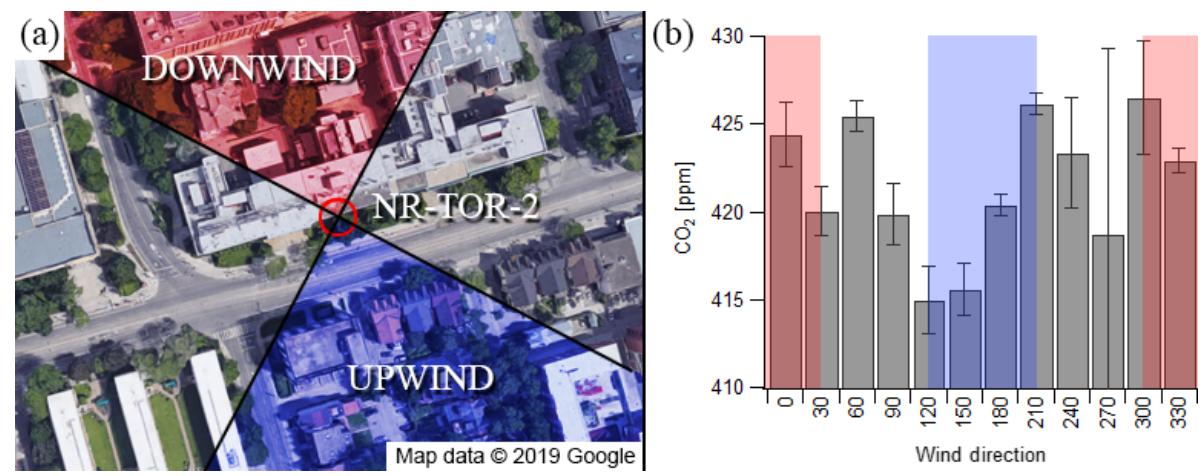

Figure 2. Satellite image of the NR-TOR-2 site, along with upwind (blue) and downwind (red) quadrant definitions. Meteorological measurements were recorded on the roof of the facility (labelled: NR-TOR-2) (a). Average ambient $\mathrm{CO}_{2}$ concentrations by wind direction, with upwind and downwind definitions again highlighted in blue and red, respectively. Error bars are $95 \%$ confidence intervals on the mean (b).

\subsubsection{Interpolation of windowed minima}

The algorithm explored in this paper is an interpolation of minimum values across a variable time window, the duration of which effectively defines, in a sense, a cut-off frequency for local and urban background signal differentiation. This algorithm was developed, validated, and utilized by Wang et al. (2018), and is described in full detail therein along with code compatible with IGOR Pro 6.37.

The background-determining function, $\psi$, takes as arguments near-road pollutant concentrations as a function of time, $C_{\mathrm{NR}}$; a window length in hours, $W$; and a smoothing factor $\alpha$. Its output is an inferred baseline for the near-road environment, $b$ :

$b=\psi\left(C_{\mathrm{NR}}, W, \alpha\right), \quad \alpha \geq 1, W \geq 3$.

In the case for which the smoothing factor, $\alpha$, is equal to 1 , the baseline function, $b$, simplifies to an interpolation of minimum values determined across $M$ windows of width $W$, where $M$ is the total number of measurements divided by $W$. In order to account for the detection of minima being biased by the range of each window, this process is repeated three times, in which the window is offset in time by floor $(W / 3)$ each time. This yields three separate functions, $b_{1}, b_{2}$, and $b_{3}$, with the final baseline, $b$, determined from the average:

$b=\psi\left(C_{\mathrm{NR}}, W, \alpha=1\right)=\frac{1}{3} \cdot \sum_{i=1}^{3} b_{i}$.

For the case in which $\alpha>1$, the process in Eqs. (4) and (5) is repeated $\alpha$ times, and the window for determining minimum values increases by a factor of $W$ each time, giving window lengths of $W, 2 W, \ldots, \alpha W$. Then, the final baseline function becomes the mean of $3 \alpha$ baseline functions, $b_{i, j}$ :

$b=\psi\left(C_{\mathrm{NR}}, W, \alpha\right)=\frac{1}{3 \alpha} \cdot \sum_{j=1}^{\alpha} \sum_{i=1}^{3} b_{i, j}$.

Thus, in addition to creating a smoother baseline output, the magnitude of the parameter $\alpha$, in conjunction with that of $W$, determines how slowly varying the resultant baseline, $b$, becomes. The effect of these input parameters can be observed 

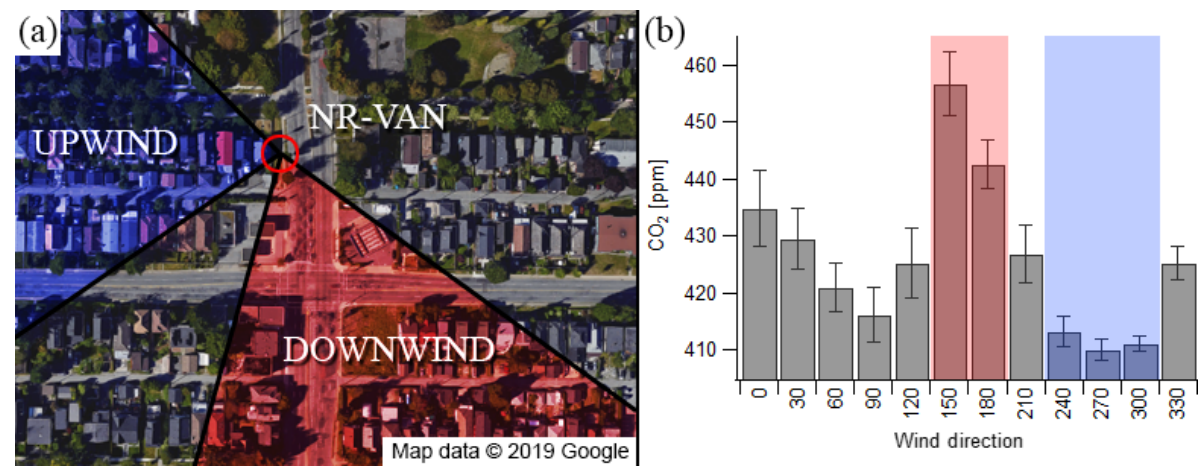

Figure 3. Satellite image of the NR-VAN site, along with upwind (blue) and downwind (red) sector definitions. Meteorological measurements were recorded on a $10 \mathrm{~m}$ mast above the station's location (labelled: NR-VAN) (a). Average ambient $\mathrm{CO}_{2}$ concentrations by wind direction, with upwind and downwind definitions again highlighted in blue and red, respectively. Error bars are $95 \%$ confidence intervals on the mean (b).

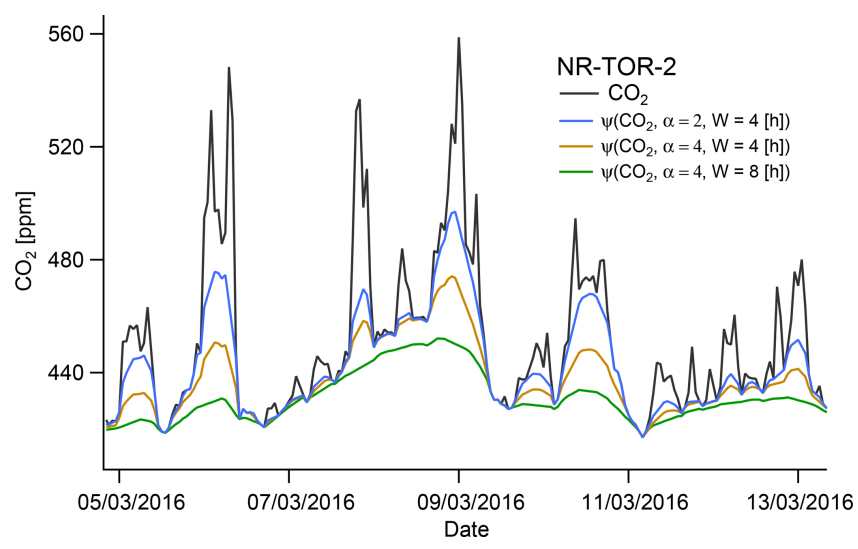

Figure 4. Method 3 applied to hourly $\mathrm{CO}_{2}$ concentrations (black) measured at NR-TOR-2. The effects of varying the input parameters $\alpha$ and $\mathrm{W}$ are shown in blue, orange, and green.

in Fig. 4, in which $\psi$ is applied to $\mathrm{CO}_{2}$ data at NR-TOR-2 for various values of $\alpha$ and $W$. If the resulting baseline function, $b$, is greater than $C_{\mathrm{NR}}$ for any point in time, it is instead set equal to $C_{\mathrm{NR}}$.

Henceforth, this algorithm shall be referred to as method 3. This method yields a baseline function, $b$, based on input near-road concentrations, $C_{\mathrm{NR}}$, constrained to yield nonnegative solutions for each observation, $i$. Average local concentrations from method $3, C_{\mathrm{L}, 3}$, were then calculated using Eqs. (7) and (8):

$C_{\mathrm{L}, 3}[i]=C_{\mathrm{NR}}[i]-b[i], \quad b[i] \leq C_{\mathrm{NR}}[i] \forall i$,

$\bar{C}_{\mathrm{L}, 3}=\frac{1}{N} \sum_{i=1}^{N} C_{\mathrm{L}, 3}[i]$.

Again, $b[i]$ values are background concentrations determined algorithmically, and are a function of $C_{\mathrm{NR}}$, whereas $C_{\mathrm{BG}}$, as in Sect. 3.1, are physically measured concentrations. It is worth noting that while the constraint $b \leq C_{\mathrm{NR}} \forall i$ as ap- plied in this algorithm, it is not always the case that a background station will measure less than a near-road station during a given hour for a number of different reasons. For example, Sofowote et al. (2018) showed that a receptor $167 \mathrm{~m}$ from the edge of Highway 401 measured $\mathrm{PM}_{2.5}$ concentrations that exceeded concurrent measurements at NR-TOR-1 ( $10 \mathrm{~m}$ from the edge of the highway) $\sim 5 \%$ of the time based on half-hourly measurements. Regardless, the impact of this assumption on estimated average local concentration is likely minimal. In using this algorithm, the width of the averaging window will affect the resulting baseline - windows that are shorter in duration will result in more temporally varying baselines, while longer windows will result in flatter baselines. For information regarding function input parameters, please refer to Wang et al. (2018). This study used the parameters $\alpha=4$ and $W=8 \mathrm{~h}$.

\subsubsection{Application to near-road ozone concentrations}

Near roadways, $\mathrm{O}_{3}$ concentrations, unlike most other pollutants considered in this study, are generally less than background concentrations. This is because $\mathrm{O}_{3}$ is formed through secondary chemistry in the troposphere, and one of its sinks is through reaction with $\mathrm{NO}$, which is a primary pollutant emitted by vehicles and is therefore often abundant near roadways. Hence, transient emissions of NO from passing vehicle plumes will result in decreases in $\mathrm{O}_{3}$ concentrations during a similar timescale. Background $\mathrm{O}_{3}$ concentrations in the near-road environment were instead estimated by interpolating maximum values rather than minima. A baseline for $\mathrm{O}_{3}(\mathrm{t})$ was established and the resulting output's sign flipped, effectively yielding an interpolation of maxima. 


\section{Results}

\subsection{Average differences between near-road and background sites}

Over the duration of the study period average $C_{\mathrm{L}, 1}$ values were calculated using method 1 , as described in Sect. 3.1, with resulting differences summarized in Tables $2-4$. Note that no $\mathrm{CO}_{2}$ difference was calculated between Vancouver stations because $\mathrm{CO}_{2}$ was not measured at BG-VAN.

The background-subtracted differences were smallest at NR-TOR-2; for every TRAP measured, both NR-TOR-1 and NR-VAN saw greater $C_{\mathrm{L}, 1}$ concentrations in comparison. This pattern is consistent with the lower traffic volumes at NR-TOR-2. Surprisingly, despite the drastic difference in traffic intensities between NR-VAN and NR-TOR$1, C_{\mathrm{L}, 1}$ values at both sites were remarkably similar for most TRAPs. This similarity was in part due to NR-VAN's closer proximity to the roadway $(6 \mathrm{~m})$ compared with NRTOR-1 $(10 \mathrm{~m})$, in conjunction with the significant fraction of diesel vehicles passing along Clark Drive (Wang et al., 2018). While most $C_{\mathrm{L}, 1}$ concentrations were similar between these two locations, UFPs at NR-TOR-1 were significantly greater $\left(3.0 \times 10^{4}\right.$ vs. $\left.1.2 \times 10^{4} \mathrm{~cm}^{-3}\right)$. However, this may in part be due to seasonal bias in UFP data availability (Table S1 in the Supplement) between NR-TOR-1 and BG-TOR-1 (note in particular the lack of concurrent data during summer months when ambient UFP concentrations are often lowest).

The $\mathrm{NO}_{2} / \mathrm{NO}_{x}$ ratios for $C_{\mathrm{L}, 1}$ at NR-TOR-2 were also markedly higher than the other near-road sites; these ratios at NR-VAN, NR-TOR-1, and NR-TOR-2 were, on average, $0.18,0.29$, and 0.61 , respectively. A potential explanation for this is the relative residence times of vehicle plumes prior to detection at each site: because NR-VAN was positioned closest to the roadway, it is likely that vehicle plumes were fresher upon detection, whereas NR-TOR-2 sampled within an urban canyon where air tends to stagnate and recirculate. These results emphasize an important implication for nearroad monitoring policies: while $\mathrm{NO}_{2}$ alone is often regulated because of associated health effects, measurements of only $\mathrm{NO}_{2}$ may not be a reliable metric for assessing near-road health impacts, as characteristics of the site may result in $\mathrm{NO}_{2}$ being a negligible fraction of total $\mathrm{NO}_{x}$.

The average differences for $\mathrm{O}_{3}$ were negative, indicating that ozone concentrations tend to be lower near major roads. Ozone is presumably being titrated due to the higher nearroad concentrations of NO. Furthermore, $\mathrm{O}_{3}$ production in downtown Toronto and metropolitan Vancouver generally occurs in a regime limited by volatile organic compounds (VOCs), meaning that the additional $\mathrm{NO}_{x}$ near roads does not enhance local ozone formation (Ainslie et al., 2013; Geddes et al., 2009).

While $\mathrm{PM}_{2.5}$ is generally considered to be a more regional and homogenous pollutant in urban environments, the observed values of $C_{\mathrm{L}, 1}\left(1.48,0.27\right.$, and $2.26 \mu \mathrm{g} \mathrm{m}^{-3}$ at NR-
TOR-1, NR-TOR-2, and NR-VAN, respectively) were found to be significantly greater than zero, and may be indicative of both primary tailpipe and non-tailpipe (e.g. brake wear, road dust resuspension) emissions. A recent study by Jeong et al. (2019) characterized the sources and composition of $\mathrm{PM}_{2.5}$ at both NR-TOR-1 and NR-TOR-2 using an Xray fluorescence continuous metals monitor. They found that while concentrations of aged organic aerosol, sulfate, and nitrate were similar between the two sites, contributions from sources such as traffic exhaust, brake wear, and road dust differed significantly, and were the primary factors responsible for differences in average $\mathrm{PM}_{2.5}$ concentrations. Another study by Sofowote et al. (2018) examined in more detail the reasons for elevated $\mathrm{PM}_{2.5}$ constituents at NR-TOR-1, with particular emphasis on $\mathrm{BC}$, relative to another receptor $167 \mathrm{~m}$ from Highway 401.

\subsection{Downwind-upwind pollutant differences}

As stated previously, NR-TOR-1 was the most ideal nearroad monitoring location in this study for associating TRAP measurements with local meteorology, as it was positioned on flat terrain, and the major roadway which it was stationed next to was the only significant source of TRAPs in the immediate area. Thus, the direction of wind at this site had a significant impact on measured pollutant concentrations (Fig. 1). Using the methods described in Sect. 3.2, hourly TRAP concentrations were aggregated based on wind direction, and were classified as being downwind, upwind, or neither. Downwind and upwind averages were calculated across the entirety of the study period and their differences, $C_{\mathrm{L}, 2}$, are also summarized in Tables 2-4. Additional information regarding the number of downwind-upwind hours and confidence intervals are provided in the Supplement (Sect. S2). Note that downwind and upwind conditions were generally not uniform with respect to time of day (Fig. S2); however, it was found that even if downwind and upwind data occurred uniformly with respect to time of day the impact it would have on average $C_{\mathrm{L}, 2}$ values is minimal for most pollutants (Tables S5 and S6).

The $C_{\mathrm{L}, 2}$ values reported in Table 2 for NR-TOR- 1 correspond relatively well with, but are higher than, respective $C_{\mathrm{L}, 1}$ values. This is true for most pollutants, with the exception of $\mathrm{O}_{3}$ and $\mathrm{PM}_{2.5}$. The reason local concentrations generated via method $2\left(C_{\mathrm{L}, 2}\right)$ are generally greater than those generated via method $1\left(C_{\mathrm{L}, 1}\right)$ is believed to be due to the following: when a site is directly downwind from a road it will generally experience the greatest TRAP concentrations, as is this case in which there is the smallest distance for dilution between the road and the site. In contrast, $C_{\mathrm{L}, 1}$ values were averaged across all meteorological scenarios. The fundamental differences between methods 1 and 2 is explored further in Sect. S3 in the Supplement. 
Table 2. Mean local pollutant concentrations at NR-TOR-1 determined using each background-subtraction method.

\begin{tabular}{lrr|rrr|rr}
\hline \multirow{2}{*}{ Pollutant } & \multicolumn{2}{c|}{ Method 1 } & \multicolumn{3}{c|}{ Method 2 } & \multicolumn{2}{c}{ Method 3 } \\
\cline { 2 - 7 } & $N(\mathrm{~h})$ & $C_{\mathrm{L}, 1} \pm 95 \% \mathrm{CI}$ & $C_{\mathrm{DW}}$ & $C_{\mathrm{UW}}$ & $C_{\mathrm{L}, 2}$ & $N(\mathrm{~h})$ & $C_{\mathrm{L}, 3 \pm 95 \% \mathrm{CI}}$ \\
\hline $\mathrm{NO}(\mathrm{ppb})$ & 14169 & $21.5 \pm 0.4$ & 37.8 & 2.9 & 34.9 & 15524 & $18.3 \pm 0.4$ \\
$\mathrm{NO}_{2}(\mathrm{ppb})$ & 13765 & $8.7 \pm 0.1$ & 21.2 & 10.7 & 10.5 & 15087 & $9.2 \pm 0.1$ \\
$\mathrm{CO}(\mathrm{ppb})$ & 6479 & $103.2 \pm 2.7$ & 364.4 & 226.6 & 137.9 & 13008 & $114.6 \pm 2.2$ \\
$\mathrm{CO}_{2}(\mathrm{ppm})$ & 7900 & $14.4 \pm 0.6$ & 437.3 & 416.4 & 20.9 & 14812 & $19.6 \pm 0.4$ \\
$\mathrm{O}_{3}(\mathrm{ppb})$ & 13753 & $-5.9 \pm 0.1$ & 15.3 & 33.2 & -17.9 & 15181 & $-12.3 \pm 0.2$ \\
$\mathrm{PM}_{2.5}\left(\mu \mathrm{g} \mathrm{m}^{-3}\right)$ & 14170 & $1.48 \pm 0.06$ & 7.68 & 9.01 & -1.33 & 15484 & $4.30 \pm 0.08$ \\
$\mathrm{UFP}\left(\mathrm{cm}^{-3}\right)$ & 5212 & $29600 \pm 800$ & 57000 & 15300 & 41700 & 12683 & $22754 \pm 449$ \\
$\mathrm{BC}\left(\mu \mathrm{g} \mathrm{m}^{-3}\right)$ & 8036 & $1.03 \pm 0.03$ & 2.13 & 0.73 & 1.4 & 15443 & $1.01 \pm 0.02$ \\
\hline
\end{tabular}

Table 3. Mean local pollutant concentrations at NR-TOR-2 determined using each background-subtraction method.

\begin{tabular}{lrr|rrr|rr}
\hline \multirow{2}{*}{ Pollutant } & \multicolumn{2}{c|}{ Method 1 } & \multicolumn{3}{c|}{ Method 2 } & \multicolumn{2}{c}{ Method 3 } \\
\cline { 2 - 7 } & $N(\mathrm{~h})$ & $C_{\mathrm{L}, 1} \pm 95 \% \mathrm{CI}$ & $C_{\mathrm{DW}}$ & $C_{\mathrm{UW}}$ & $C_{\mathrm{L}, 2}$ & $N(\mathrm{~h})$ & $C_{\mathrm{L}, 3} \pm 95 \% \mathrm{CI}$ \\
\hline $\mathrm{NO}(\mathrm{ppb})$ & 13768 & $3.5 \pm 0.1$ & 6 & 3.2 & 2.8 & 14937 & $3.8 \pm 0.1$ \\
$\mathrm{NO}_{2}(\mathrm{ppb})$ & 11211 & $5.4 \pm 0.1$ & 8.5 & 10.4 & -1.9 & 12359 & $5.3 \pm 0.1$ \\
$\mathrm{CO}(\mathrm{ppb})$ & 13603 & $72.3 \pm 1.5$ & 247.9 & 246.8 & 1.1 & 15152 & $68.7 \pm 1.3$ \\
$\mathrm{CO}_{2}(\mathrm{ppm})$ & 10686 & $10.6 \pm 0.4$ & 423.1 & 421.4 & 1.7 & 14626 & $13.3 \pm 0.2$ \\
$\mathrm{O}_{3}(\mathrm{ppb})$ & 15109 & $-2.9 \pm 0.1$ & 24.2 & 28.7 & -4.5 & 15827 & $-9.0 \pm 0.1$ \\
$\mathrm{PM}_{2.5}\left(\mu \mathrm{g} \mathrm{m}^{-3}\right)$ & 15193 & $0.27 \pm 0.05$ & 3.8 & 9.01 & -5.21 & 15730 & $2.92 \pm 0.06$ \\
$\mathrm{UFP}\left(\mathrm{cm}^{-3}\right)$ & 7400 & $7400 \pm 200$ & 12900 & 16700 & -3800 & 14931 & $7088 \pm 108$ \\
$\mathrm{BC}\left(\mu \mathrm{g} \mathrm{m}^{-3}\right)$ & 14740 & $0.34 \pm 0.01$ & 0.63 & 0.81 & -0.18 & 15451 & $0.41 \pm 0.01$ \\
\hline
\end{tabular}

Unlike NR-TOR-1, NR-TOR-2 was not an ideal site for applying method 2 in a straightforward manner, as it measured air samples within an urban canyon where micrometeorology was complicated by vortices, stagnation, and recirculation effects. Using the downwind and upwind sector definitions in Sect. 3.2.2, $C_{\mathrm{L}, 2}$ values were calculated at NRTOR-2 and are summarized in Table 3. This methodology of contrasting downwind and upwind pollutant averages at NR-TOR-2 was unable to produce meaningful differences and the resulting disagreement with the differences between near-road and urban background measurements $\left(C_{\mathrm{L}, 1}\right)$ is evident. Associating ground-level TRAP concentrations with city-scale meteorology at this site was complicated by surrounding urban architecture and the presence of an intersection approximately $50 \mathrm{~m} \mathrm{SW}$ of the receptor. In actuality, the difference calculated for this site was between that of leeward and windward in-canyon concentrations, and this difference was not as substantial as the NR-TOR-2 and BGTOR-2 average site difference. For these reasons, associating near-road pollutant concentrations with meteorological data was not an effective way of differentiating between local and regional influences on pollutant concentrations at this particular near-road site. In general, in order to attain this differentiation for measurements made in urban canyons, more complicated meteorological models are necessary; hence, simple downwind-upwind differences are not universally applica- ble to near-road monitoring data, especially for locations in heavily urbanized landscapes.

Lastly, the siting of NR-VAN was somewhere between NR-TOR-1 and NR-TOR-2 in terms of complexity in associating TRAP concentrations with meteorology. The presence of densely spaced residential buildings within the immediate vicinity of the measurement station resulted in surface roughness having an effect on winds carrying TRAPs from major roadways farther away. Despite this, the differences between average downwind and upwind TRAP concentrations at NR-VAN were similar to, albeit larger, than the NR-VAN-BG-VAN differences in Table 4, a result similar to that for NR-TOR-1. The fact that consistent results were seen for NR-VAN and NR-TOR-1 but not NR-TOR-2 underlines the importance of a station's location, surrounding obstructions to winds, and location of traffic sources and that associating near-road TRAP concentrations with meteorological variability should be done with caution, taking into account the subtleties of each site's environment. The apparent stronger influence of the intersection rather than traffic directly next to NR-VAN (i.e. winds originating from $90^{\circ}$; see Fig. 3), despite Clark Drive being $6 \mathrm{~m}$ vs. the intersection being $65 \mathrm{~m}$ away, may seem paradoxical. We speculate that the acceleration of southbound traffic along Clark Drive at this intersection was the main source of emissions, while 
Table 4. Mean local pollutant concentrations at NR-VAN determined using each background-subtraction method.

\begin{tabular}{lrr|rrr|rr}
\hline Pollutant & \multicolumn{2}{c|}{ Method 1 } & \multicolumn{3}{c|}{ Method 2 } & \multicolumn{2}{c}{ Method 3 } \\
\cline { 2 - 7 } & $N(\mathrm{~h})$ & $C_{\mathrm{L}, 1} \pm 95 \% \mathrm{CI}$ & $C_{\mathrm{DW}}$ & $C_{\mathrm{UW}}$ & $C_{\mathrm{L}, 2}$ & $N(\mathrm{~h})$ & $C_{\mathrm{L}, 3} \pm 95 \% \mathrm{CI}$ \\
\hline $\mathrm{NO}(\mathrm{ppb})$ & 10647 & $23.0 \pm 0.5$ & 56.6 & 9.7 & 46.8 & 15134 & $27.6 \pm 0.6$ \\
$\mathrm{NO}_{2}(\mathrm{ppb})$ & 10666 & $5.1 \pm 0.1$ & 21.9 & 11.5 & 10.4 & 15148 & $9.7 \pm 0.1$ \\
$\mathrm{CO}(\mathrm{ppb})$ & 9435 & $95.7 \pm 2.3$ & 414.3 & 210.1 & 204.2 & 13935 & $153.3 \pm 3.4$ \\
$\mathrm{CO}_{2}(\mathrm{ppm})$ & - & - & 461.6 & 414.5 & 47.1 & 13503 & $39.0 \pm 0.7$ \\
$\mathrm{O}_{3}(\mathrm{ppb})$ & 10535 & $-3.9 \pm 0.1$ & 9.4 & 19.7 & -10.3 & 15016 & $-10.6 \pm 0.1$ \\
$\mathrm{PM}_{2.5}\left(\mu \mathrm{g} \mathrm{m}^{-3}\right)$ & 10491 & $2.26 \pm 0.07$ & 8.81 & 5.57 & 3.23 & 14879 & $3.99 \pm 0.10$ \\
$\mathrm{UFP}\left(\mathrm{cm}^{-3}\right)$ & 9452 & $11600 \pm 300$ & 30000 & 14000 & 16000 & 14463 & $15252 \pm 251$ \\
$\mathrm{BC}\left(\mu \mathrm{g} \mathrm{m}^{-3}\right)$ & 10728 & $1.18 \pm 0.02$ & 2.48 & 0.84 & 1.64 & 15312 & $1.26 \pm 0.02$ \\
\hline
\end{tabular}

coasting past the site, particularly when slowing down for the stoplight, would have contributed much less.

\subsection{Local concentrations inferred from baseline subtraction}

Method 3, as described in Sect. 3.3.1, was applied to hourly pollutant concentrations, and the algorithm input parameters used were $\alpha=4$ and $W=8 \mathrm{~h}$. From the output, $C_{\mathrm{L}, 3}$ was determined as a function of time, and then averaged across the entirety of the measurement campaign; the resultant averages are summarized in Tables 2-4 for each near-road site.

A benefit to this method was that it was able to estimate local and background $\mathrm{CO}_{2}$ concentrations at NR-VAN, where $\mathrm{CO}_{2}$ measurements were made only in the near-road environment and not at the background site. This emphasizes a key advantage to approaches such as these: traffic-related signal can be isolated from near-road measurements alone, without the need for background or even meteorological measurements. Furthermore, this differentiation was performed on an hourly basis, thereby retaining information in the time domain, which was not possible with method 2.

Across all near-road locations, average $C_{\mathrm{L}, 3}$ concentrations were quite similar to respective average $C_{\mathrm{L}, 1}$ values, implying that method 3 , which uses only near-road data, is a robust means of estimating urban background and local traffic-related pollutant concentrations. This was true even for NR-TOR-2, where micrometeorology complicated analysis using method 2. Fine particulate matter was an exception to this, however. Regarding $\mathrm{PM}_{2.5}$, because its signal was largely dominated by regional-scale sources and dynamics, temporal fluctuations in roadside $\mathrm{PM}_{2.5}$ concentrations generally varied more slowly than those of primary pollutants such as NO or BC, for example. Furthermore, this variability is generally meteorologically driven and occurs homogeneously over large areas (tens of kilometres); we posit that these variabilities associated with meteorology were falsely attributed to local signal, causing local $\mathrm{PM}_{2.5}$ concentrations ascertained through this method to be much higher than respective $C_{\mathrm{L}, 1}$ concentrations. Lastly, for ambient concentra- tions $<80 \mu \mathrm{g} \mathrm{m}^{-3}$, the hourly precision of the SHARP 5030 is $\pm 2 \mu \mathrm{g} \mathrm{m}^{-3}$. So, the average site differences between nearroad and background sites, which are all around $2 \mu \mathrm{g} \mathrm{m}^{-3}$ or less, are likely too small for method 3 to isolate as the signalto-noise ratio on an hourly basis is quite small.

The choice of time window parameter, when comparing results obtained from method 1 , is both site-specific and pollutant-dependent. For example, shorter time windows will produce results that are in better agreement with stations that are closer in proximity. Further, the role of secondary chemistry will affect agreement between method 1 and method 3. Variability in $C_{\mathrm{L}, 3}$ is shown in Table $\mathrm{S} 9$, where average $C_{\mathrm{L}, 3}$ values are reported for $W=6$ and $W=14$. When comparing average $C_{\mathrm{L}, 3}$ values to average $C_{\mathrm{L}, 1}$ values as a function of $W$, it appears as though some pollutants produce better agreement for smaller $W$ values (e.g. $\mathrm{CO}_{2}$ and $\mathrm{PM}_{2.5}$ ), whereas others agree better for larger values of $W$ (e.g. UFPs). This is likely due to the relative homogeneity of $\mathrm{PM}_{2.5}$ and $\mathrm{CO}_{2}$ and heterogeneity of UFP concentrations in urban environments. Generally, however, it appears that the values $\alpha=4$ and $W=8 \mathrm{~h}$ are an appropriate middle ground for the pollutants considered in this study, and likely represent an urban background spatial scale of between 5 and $10 \mathrm{~km}$.

Although application of method 3 was less suitable for some pollutants (i.e. $\mathrm{PM}_{2.5}$ ), it appears to behave in an accurate and robust manner for most others. Comparing $C_{\mathrm{L}, 1}$ and $C_{\mathrm{L}, 3}$ values in Tables $2-4$, it appears that method 3 produced similar results when compared with method 1 , with the added benefit of retaining information in the time domain and not requiring a second site. It is worth emphasizing that method 3 was an independently developed method for background-subtracting near-road data without the need for concurrent background measurements. The parameters $\alpha=4$ and $W=8 \mathrm{~h}$ were originally chosen to be generalizable for near-road measurements, and to differentiate similar local/regional scales. While a direct comparison with method 1 to assess the accuracy of method 3 is tempting, method 1 is not without its own limitations (i.e. differences in distance between near-road and background stations, difficulty 
in removing background stations from local sources). Thus, while this comparison is useful for understanding the spatial scales of different pollutants, background-subtraction parameters should not necessarily be chosen based on this alone.

\subsection{Comparison of background subtraction methods}

Three techniques were applied to the near-road monitoring locations in this study to extract information regarding local TRAP concentrations: (1) average differences between near-road and urban background locations, (2) downwindupwind differences in near-road measurements, and (3) average concentrations inferred through time-series analysis of near-road data. Generally, methods 1 and 3 agreed well with one another, whereas method 2 produced values that were high in comparison with the other two methods at NR-TOR1 and NR-VAN, and generated results that were close to zero at NR-TOR-2. A comparison of the three methodologies is summarized graphically in the Supplement (Figs. S4-S6). The close agreement of methods 1 and 3, which describe the average concentrations attributed to local traffic, is encouraging, suggesting a background is inferable from near-road data alone using method 3. Method 2 was able to isolate trafficrelated pollutant signal for NR-VAN and NR-TOR-1, but was not feasible for NR-TOR-2, thus highlighting a drawback of relying exclusively on wind direction data for source apportionment efforts. It is believed that method 2, while useful for isolating traffic-related pollution, is less relevant for epidemiological purposes as it only considers certain meteorological scenarios.

\subsection{Application of local concentrations}

Subtraction of background concentrations allows the influences of local traffic on near-road TRAP concentrations to be assessed. The benefits in terms of improved understanding were examined and illustrated by applying the local concentrations thereby derived in two ways. The degree to which traffic influences TRAP concentrations beside a road can vary day to day depending on the prevailing meteorology. Using the local signal allowed the magnitude of this source of variability to be assessed in a manner that is consistent across most TRAPs and across all near-road sites. In contrast, the contribution of traffic to the total concentration will differ across pollutants. For example, some pollutants such as NO may be predominantly from traffic while others such as $\mathrm{CO}_{2}$ will be dominated by the background. Separating the local and background concentrations allowed assessment of how the portion from local traffic varied between sites and across the pollutants. Effectively, the background subtraction methodology provided estimates that illustrate how much concentrations beside a road would drop if all the traffic on that road were to be removed, as concentrations would converge to that of the urban background in that case.

\subsubsection{Effect of meteorology on local TRAP variability}

Using the hourly values of $C_{\mathrm{L}, 3}$ at each near-road station determined using method 3 in Sect. 3.3.1, the roles of individual meteorological parameters in the variability of these local concentrations were explored. While roadside concentrations are affected by meteorology in a number of ways, local pollutant quantities - of interest are those from vehicular exhaust are expected to behave in a more predictable manner in comparison, and indeed there are many means by which to predict the evolution of these exhaust plumes, from simple dispersion models to computational fluid dynamics. Here, however, a more simplified means of underlining the effect of wind on above-background TRAP concentrations was utilized: local TRAP concentrations normalized to their mean values were associated with both the direction and speed of local winds, the former showing the effect of downwind-upwind variability and the latter showing that of dilution. Normalization allowed results to be more comparable between sites and pollutants where mean emission rates of TRAPs may differ. While different receptor distances from a roadway will lead to different absolute concentrations measured, it is assumed here that when these concentrations are normalized to their mean that the trends with respect to meteorology will be similar. Because NR-TOR-2 was situated within an urban canyon, the effect of meteorology on its measured concentrations was not relatable to the other two stations in this study; for this reason it is omitted from this section.

\subsubsection{Wind direction}

Wind direction can have a large influence on roadside TRAP concentrations. Shown in Fig. 5 is the dependence of normalized local pollutant concentrations on wind direction at both NR-VAN and NR-TOR-1. Generally, downwind measurements have the effect of enhancing local concentrations by a factor of $\sim 1.5-2.0$, whereas upwind conditions suppress local concentrations by a factor of $\sim 4.0$, with respect to the mean. Note that these upwind concentrations did not necessarily converge to zero as hourly averages were used to create these trends. It is also conceivable that during upwind periods, local turbulence from traffic and/or brief shifts in wind direction resulted in some degree of plume capture. It would appear that, on an hourly-averaged basis, traffic's contribution to local TRAP variability (i.e. irrespective of background pollution) at a near-road receptor may change by a factor of 6 to 8 depending on the average direction of wind.

As shown in Fig. 5, a clear sinusoidal wind direction dependency is apparent at NR-VAN and NR-TOR-1, with similar ranges in enhancement and suppression at both sites. However, at NR-VAN, there appears to be two modes in concentration enhancement. The Clark Drive and 12th Avenue intersection, located approximately $65 \mathrm{~m}$ from the receptor, had an influence on local TRAPs originating from the south. However, given its distance, west- and eastbound 

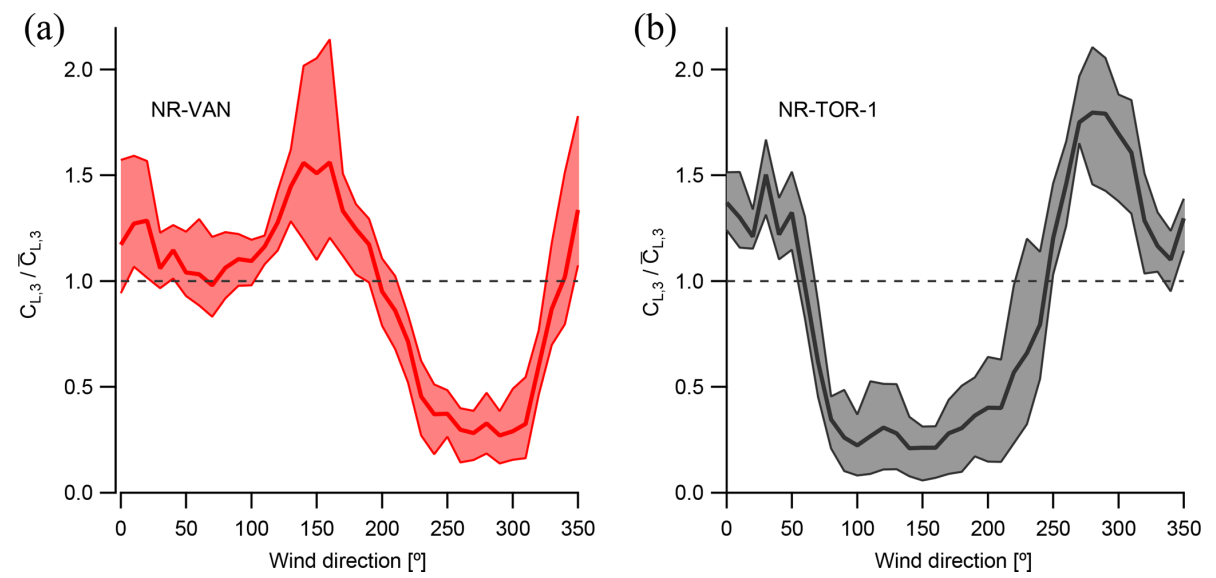

Figure 5. Normalized local pollutant concentrations determined using method 3 as a function of wind direction at NR-VAN (a) and NRTOR-1 (b). Solid lines indicate the average trend amongst all TRAPs, and shaded areas indicate the range of variability between TRAPs.

traffic along 12th Avenue should not have had an influence similar to that of Clark Drive, which was only $6 \mathrm{~m}$ away. We postulate that the traffic lights at the intersection caused stopand-go patterns in which southbound traffic on Clark Drive was often backed up to the monitoring location, and it is these driving patterns that are believed to be associated with the enhancement seen between the wind directions of 100 and $200^{\circ}$ at NR-VAN.

When comparing methods of background subtraction, it was shown that method 2 yielded higher estimates of the local concentrations in comparison with the other two methodologies, as further explored in Sect. S3 of the Supplement. Across pollutants, it was found that on average this downwind-upwind difference resulted in local TRAP concentrations that were factors of 1.3 and 1.4 times greater than those inferred from method 1 at NR-VAN and NRTOR-1, respectively (Table S8). In short, this corresponds well with above-average normalized local pollutant concentrations during downwind conditions at both sites (Fig. 5), during which conditions values of $C_{\mathrm{L}, 3}$ were found to be similar factors greater than the mean at both sites (Table S8).

Lastly, it is of interest to note that hourly upwind $C_{\mathrm{L}, 3}$ concentrations at either site yielded non-zero local concentrations. It is indeed likely that at an hourly time resolution some plume capture will occur during predominately upwind conditions; however, this seems to carry with it the implication that upwind analysis at a near-road location may overestimate background concentrations. To test this, average upwind concentrations were compared with average concentrations measured at each nearest background location, the results of which are summarized in Table S7. Generally, the two appear to agree well with one another, and so any plume capture during upwind conditions apparently produced a negligible impact on total concentrations.

\subsubsection{Wind speed}

Similar to the analysis in the previous section, the effect of wind speed on roadside TRAP concentrations was explored at NR-TOR-1 and NR-VAN, and consistent results were found between them. Under stagnant conditions (wind speeds of $\sim 1.0 \mathrm{~m} \mathrm{~s}^{-1}$ ), local pollutant quantities were found to be enhanced by factors of $\sim 2.0$ and $\sim 1.7$ at NR-VAN and NR-TOR-1, respectively, and high wind speeds $\left(>10 \mathrm{~m} \mathrm{~s}^{-1}\right)$ suppressed these quantities by a factor of $\sim 2.0$ at both sites (Fig. 6), giving an overall influence factor of 3.4 to 4 . The maximum levels of enhancement and suppression were slightly smaller than the results found for wind direction, implying a slightly smaller or equivalent importance for local TRAP concentrations at a given roadside receptor. The relation used to model the effect of wind speed on normalized local concentrations was the following:

$\frac{C_{\mathrm{L}, 3}}{\bar{C}_{\mathrm{L}, 3}}=\frac{c_{1}}{\mathrm{WS}^{c_{2}}}$,

where $C_{\mathrm{L}, 3}$ represents local pollutant concentrations determined through method $3, c_{1}$ and $c_{2}$ are regression parameters, and WS is wind speed as measured at the station. Indeed, more involved models have been shown to better represent the wind speed dependency of specific pollutants (Jones et al., 2010); however, simplicity is preferred here so as to generalize results across sites and pollutants.

On average, the regression parameters $c_{1}$ and $c_{2}$ were found to be $\sim 2.0$ and $\sim 0.6$ for NR-VAN and $\sim 1.6$ and $\sim 0.5$ for NR-TOR-1, respectively (Table S10). Section S5.1 in the Supplement compares these results between weekdays and weekends. While different $c_{1}$ parameters were determined for both sites, presumably due to their difference in roadway proximity, similar $c_{2}$ parameters between 0.5 and 0.6 were found. The $c_{2}$ parameter, which embodies the wind speed-pollutant decay relationship, is expected to be independent of a station's proximity to the roadway. As with the 

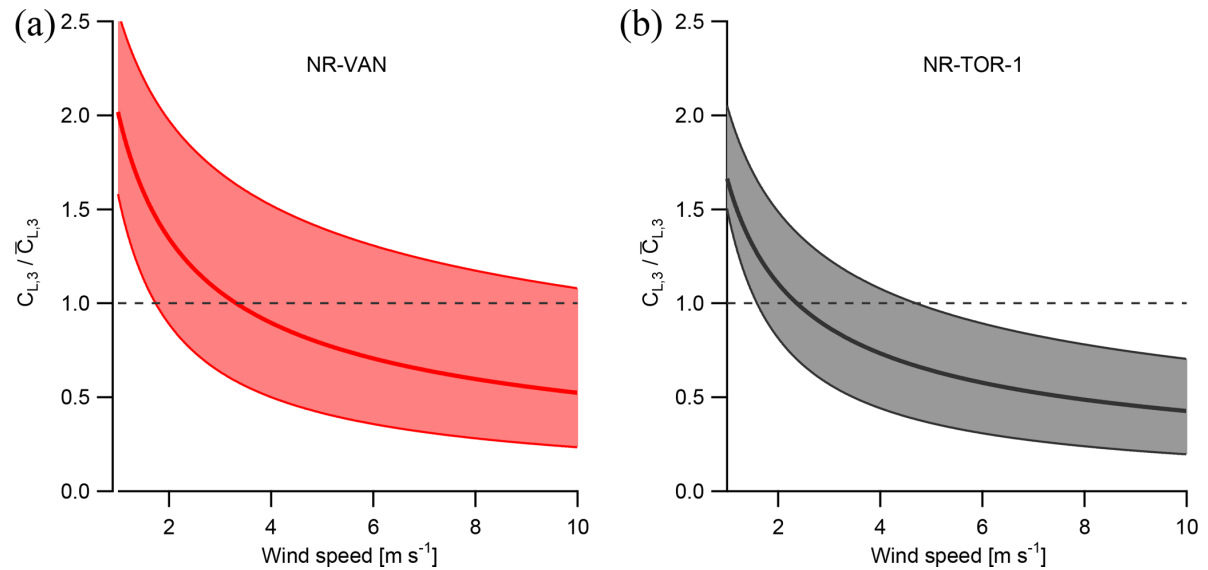

Figure 6. Normalized local pollutant concentrations determined using method 3 as a function of wind speed at NR-VAN (a) and NR-TOR-1 (b). Solid lines indicate the average trend amongst all TRAPs, and shaded areas indicate the range of variability between TRAPs.

wind direction analysis in the previous section, these associations with respect to wind speed were averaged from 2 years of hourly data across the entire study domain, meaning they were acquired from a range of pollutants, traffic conditions, wind directions, and times of day. While less descriptive from a mechanistic perspective, these results are intended to be more representative of the ranges of variability in average above-background exposure levels in the immediate area.

\subsection{Fraction of near-road pollution attributable to local sources}

The time-series-based estimates of the background concentrations were also applied to estimate the portion of the pollutant concentrations that were due to local traffic. For example approximately half of total $\mathrm{BC}$ concentrations were estimated to be due to local sources at NR-TOR-1 with lower and higher percent contributions at NR-TOR-2 and NR-VAN, respectively (Fig. 7). The contribution of local sources varied across the pollutants; NO had the highest local contribution at the near-road sites while $\mathrm{CO}_{2}$ had the lowest (Fig. 8). Further, this methodology was able to replicate trends in weekday-weekend background pollution variability - shown in Fig. 7 is BC, for example, with others in the Supplement (Figs. S7-S12). Local components of air pollution showed far greater differences between weekdays and weekends at each near-road monitoring location, emphasizing the effect of different on-road traffic conditions between these two sets of days. Generally, TRAP concentrations measured at urban background sites were slightly higher on weekdays compared to weekends, and this change in regional pollution was captured in the background contributions extracted from the near-road data. It should be expected that average concentrations measured at BG-TOR-1 should match the background elements of NR-TOR-1 reasonably well, with a similar argument to be made for BG-TOR-2 and NR-TOR-2; however,

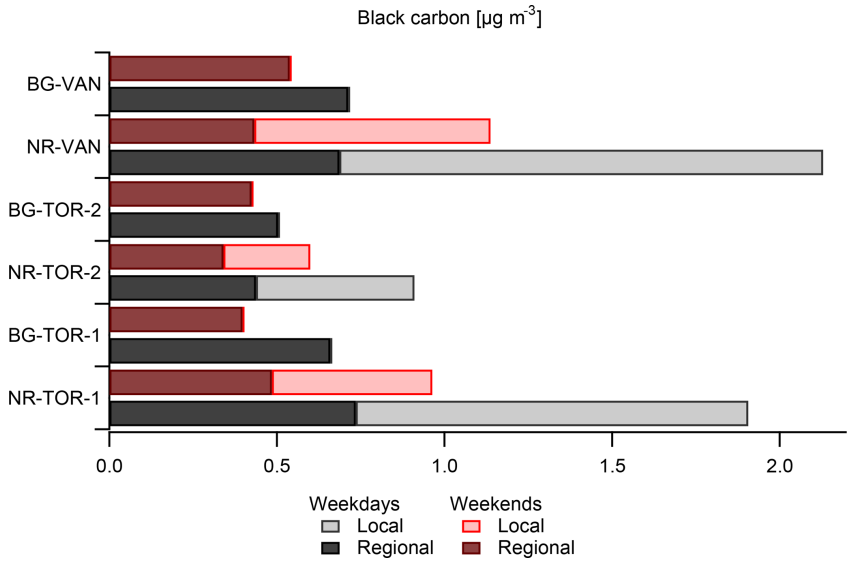

Figure 7. Black carbon concentrations at each monitoring location in this study. Each site is separated by weekday and weekend, and bars are stacked according to concentrations attributed to local and regional sources. Background stations are presumed fully regional and therefore contain no local component.

these urban background concentrations are likely not perfectly homogeneous throughout the city. The spatial difference between BG-TOR-1 in north Toronto and BG-TOR-2 in south Toronto was $20 \mathrm{~km}$, and the difference in average pollutant levels between the two reflects this.

\section{Conclusions}

In this study TRAP concentrations were measured continuously at time resolutions of $1 \mathrm{~h}$ or finer for over 2 years at three near-road and three urban background locations. Three methods were explored for estimating the contribution of local and regional/background sources to near-road measurements: differences between average measurements taken near the road and at a nearby urban background location, 


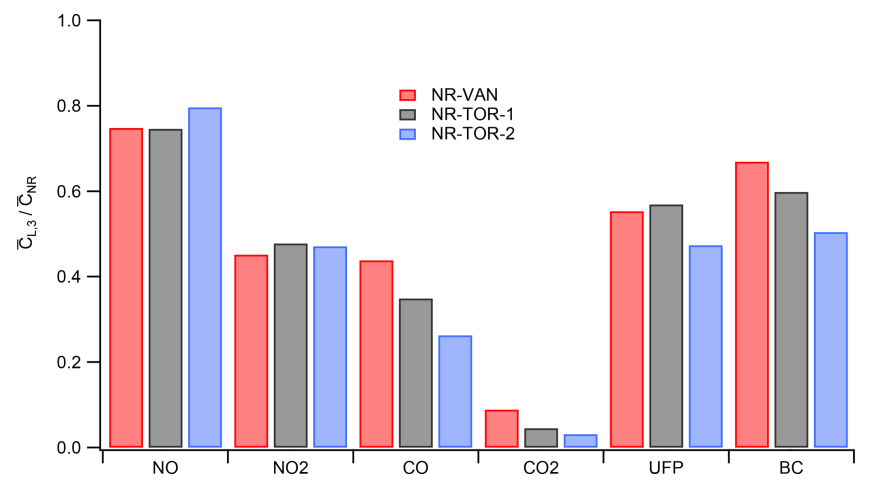

Figure 8. Average fraction of near-road measurements attributed to local sources, as determined by method 3 , for each near-road monitoring location.

downwind-upwind analysis at the near-road location, and time-series analysis of near-road pollutant data. Generally, the near-road vs. urban background and time-series analysis methods produced results that were in good agreement; these values represent contributions to TRAP due to local traffic averaged over all wind directions. The downwind-upwind method yielded local concentrations that were higher than the average station differences by approximately $40 \%$; this was attributable to the downwind-upwind analysis isolating the conditions where traffic has the greatest impact on a site while the average differences included data across all wind conditions.

The time-series analysis method was an accurate and robust means of differentiating local and regional signal, with the added benefits of being applicable across all near-road sites, not being constrained to certain meteorological scenarios or requiring a separate background site, and retaining information in the time domain. This methodology is recommended for future use in applications such as determining the impact of local on-road traffic to a roadside receptor, isolating background concentrations from ambient data for use in dispersion modelling, and obtaining above-background concentrations for fleet emission factor calculations, for example.

Lastly, to demonstrate the value in isolating the influence of local sources at an hourly time resolution, local TRAP concentrations determined using time-series analysis were compared with meteorological variables at two of the near-road sites, NR-VAN and NR-TOR-1. This analysis yielded trends that were similar between sites and generalizable across all measured pollutants, with the exception of $\mathrm{PM}_{2.5}$ and $\mathrm{O}_{3}$. Wind direction had a factor of influence of approximately 7 at both near-road sites, while the effect of wind speed was found to be slightly smaller, varying local hourly concentrations by a factor of 4 , with the highest concentrations seen during stagnant conditions and the lowest concentrations as wind speed became large. Both sites exhibited similar decays in local concentration with respect to wind speed; proportionality to wind speed was found to be between $\mathrm{WS}^{-0.5}$ and $\mathrm{WS}^{-0.6}$.

Data availability. Data will become available for download at: http://hdl.handle.net/1807/96668 on 1 December 2020.

Supplement. The supplement related to this article is available online at: https://doi.org/10.5194/amt-12-5247-2019-supplement.

Author contributions. AM, LW, CA, DH, JRB, and GJE designed and initiated the near-road monitoring study. Data collection and quality assurance from Toronto stations was performed by $\mathrm{NH}$, JMW, CHJ, RMH, US, JD, YS, and MN, while GD was responsible for the two stations in Vancouver. NH prepared the paper, with contributions from all co-authors, and performed all data analysis.

Competing interests. The authors declare that they have no conflict of interest.

Acknowledgements. We would like to thank all partners involved in the near-road monitoring pilot project in Canada, including staff from Metro Vancouver, the Ontario Ministry of the Environment Conservation and Parks, and Environment and Climate Change Canada for their assistance in formulating the design of the study as well as deploying and maintaining the air quality instruments used in this study.

Review statement. This paper was edited by Marc von Hobe and reviewed by three anonymous referees.

\section{References}

Ainslie, B., Steyn, D. G., Reuten, C., and Jackson, P. L.: A Retrospective Analysis of Ozone Formation in the Lower Fraser Valley, British Columbia, Canada, Part II: Influence of Emissions Reductions on Ozone Formation, Atmos. Ocean., 51, 170-186, https://doi.org/10.1080/07055900.2013.782264, 2013.

Baldwin, N., Gilani, O., Raja, S., Batterman, S., Ganguly, R., Hopke, P., Berrocal, V., Robins, T., and Hoogterp, S.: Factors affecting pollutant concentrations in the near-road environment, Atmos. Environ., 115, 223-235, https://doi.org/10.1016/j.atmosenv.2015.05.024, 2015.

Belis, C. A., Karaguilian, F., Larsen, B. R., and Hopke, P. K.: Critical review and meta-analysis of ambient particulate matter source apportionment using receptor models in Europe, Atmos. Environ., 69, 94-108, https://doi.org/10.1016/j.atmosenv.2012.11.009, 2013.

Brantley, H. L., Hagler, G. S. W., Kimbrough, E. S., Williams, R. W., Mukerjee, S., and Neas, L. M.: Mobile air monitoring dataprocessing strategies and effects on spatial air pollution trends, 
Atmos. Meas. Tech., 7, 2169-2183, https://doi.org/10.5194/amt7-2169-2014, 2014.

Evans, G. J., Jeong, C.-H., Sabaliauskas, K., Jadidian, P., Aldersley, S., Larocque, H., and Herod, D.: Design of a Near-Road Monitoring Strategy for Canada, A Final Report to Environment Canada, SOCAAR, Toronto, 1-60, 2011.

Galvis, B., Bergin, M., and Russell, A.: Fuel-based fine particulate and black carbon emission factors from a railyard in Atlanta, J. Air. Waste. Manage., 63, 648-658, https://doi.org/10.1080/10962247.2013.776507, 2013.

Geddes, J. A., Murphy, J. G., and Wang, D. K.: Long term changes in nitrogen oxides and volatile organic compounds in Toronto and the challenges facing local ozone control, Atmos. Environ., 43, 3407-3415, https://doi.org/10.1016/j.atmosenv.2009.03.053, 2009.

Gomez-Losada, A., Pires, J. C. M., and Pino-Mejias, R.: Modelling background air pollution exposure in urban environments: Implications for epidemiological research, Environ. Modell. Soft., 106, 13-21, https://doi.org/10.1016/j.envsoft.2018.02.011, 2018.

Jeong, C.-H., Evans, G. J., Healy, R. M., Jadidian, P., Wentzell, J., Liggio, J., and Brook, J. R.: Rapid physical and chemical transformation of traffic-related atmospheric particles near a highway, Atmos. Pollut. Res., 6, 662-672, https://doi.org/10.5094/APR.2015.075, 2015.

Jeong, C.-H., Wang, J. M., Hilker, N., Debosz, J., Sofowote, U., Su, Y., Noble, M., Healy, R. M., Munoz, T., Dabek-Zlotorzynska, E., Celo, V., White, L., Audette, C., Herod, D., and Evans, G. J.: Temporal and spatial variability of traffic-related $\mathrm{PM}_{2.5}$ sources: Comparison of exhaust and non-exhaust emissions, Atmos. Environ., 198, 55-69, https://doi.org/10.1016/j.atmosenv.2018.10.038, 2019.

Jones, A. M., Harrison, R. M., and Baker, J.: The wind speed dependency of the concentrations of airborne particulate matter and $\mathrm{NO}_{x}$, Atmos. Environ., 44, 1682-1690, https://doi.org/10.1016/j.atmosenv.2010.01.007, 2010.

Kimbrough, S., Hanley, T., Hagler, G., Baldauf, R., Snyder, M., and Brantley, H.: Influential factors affecting black carbon trends at four sites of differing distance from a major highway in Las Vegas, Air. Qual. Atmos. Hlth., 11, 181-196, https://doi.org/10.1007/s11869-017-0519-3, 2018.

Klems, J. P., Pennington, M. R., Zordan, C. A., and Johnston, M. V.: Ultrafine Particles Near a Roadway Intersection: Origin and Apportionment of Fast Changes in Concentration, Environ. Sci. Technol., 44, 7903-7907, https://doi.org/10.1021/es102009e, 2010.

Ma, N. and Birmili, W.: Estimating the contribution of photochemical particle formation to ultrafine particle number averages in an urban atmosphere, Sci. Total. Environ., 512-513, 154-166, https://doi.org/10.1016/j.scitotenv.2015.01.009, 2015.

Molina, M. J. and Molina, L. T.: Megacities and Atmospheric Pollution, J. Air. Waste. Manage., 54, 644-680, https://doi.org/10.1080/10473289.2004.10470936, 2004.
Oke, T. R.: Street Design and Urban Canopy Layer Climate, Energ. Buildings., 11, 103-113, https://doi.org/10.1016/03787788(88)90026-6, 1988.

Pant, P. and Harrison, R. M.: Estimation of the contribution of road traffic emissions to particulate matter concentrations from field measurements: A review, Atmos. Environ., 77, 78-97, https://doi.org/10.1016/j.atmosenv.2013.04.028, 2013.

Sabaliauskas, K., Jeong, C.-H., Yao, X., Jun, Y.-S., Jadidian, P., and Evans, G. J.: Five-year roadside measurements of ultrafine particle in a major Canadian city, Atmos. Environ., 49, 245-256, https://doi.org/10.1016/j.atmosenv.2011.11.052, 2012.

Sabaliauskas, K., Jeong, C.-H., Yao, X., and Evans, G. J.: The application of wavelet decomposition to quantify the local and regional sources of ultrafine particles in cities, Atmos. Environ., 95, 249-257, https://doi.org/10.1016/j.atmosenv.2014.05.035, 2014.

Saha, P. K., Khlystov, A., Snyder, M. G., and Grieshop, A. P.: Characterization of air pollutant concentrations, fleet emission factors, and dispersion near a North Carolina interstate freeway across two seasons, Atmos. Environ., 177, 143-153, https://doi.org/10.1016/j.atmosenv.2018.01.019, 2018.

Shairsingh, K. K., Jeong, C-H., Wang, J. M., and Evans, G. J.: Characterizing the spatial variability of local and background concentration signals for air pollution at the neighbourhood scale, Atmos. Environ., 183, 57-68, https://doi.org/10.1016/j.atmosenv.2018.04.010, 2018.

Sofowote, U. M., Healy, R. M., Su, Y., Debosz, J., Noble, M., Munoz, A., Jeong, C-H., Wang, J. M., Hilker, N., Evans, G. J., and Hopke, P. K.: Understanding the $\mathrm{PM}_{2.5}$ imbalance between a far and near-road location: Results of high temporal frequency source apportionment and parameterization of black carbon, Atmos. Environ., 173, 277-288, https://doi.org/10.1016/j.atmosenv.2017.10.063, 2018.

Tchepel, O. and Borrego, C.: Frequency analysis of air quality time series for traffic related pollutants, J. Environ. Monitor., 12, 544 550, https://doi.org/10.1039/b913797a, 2010.

Vardoulakis, S., Fisher, B. E. A., Pericleous, K., and GonzalezFlesca, N.: Modelling air quality in street canyons: a review, Atmos. Environ., 37, 155-182, https://doi.org/10.1016/S13522310(02)00857-9, 2003.

Wang, J. M., Jeong, C.-H., Zimmerman, N., Healy, R. M., Wang, D. K., Ke, F., and Evans, G. J.: Plume-based analysis of vehicle fleet air pollutant emissions and the contribution from high emitters, Atmos. Meas. Tech., 8, 3263-3275, https://doi.org/10.5194/amt8-3263-2015, 2015.

Wang, J. M., Jeong, C-H., Hilker, N., Shairsingh, K. K., Healy, R. M., Sofowote, U., Debosz, J., Su, Y., McGaughey, M., Doerksen, G., Munoz, T., White, L., Herod, D., and Evans, G. J.: Near-Road Air Pollutant Measurements: Accounting for Inter-Site Variability Using Emission Factors, Environ. Sci. Technol., 52, 94959504, https://doi.org/10.1021/acs.est.8b01914, 2018. 